\title{
Association between Subclinical Low Serum 25(OH)D in Donors and Fatty Liver Disease in Recipients after Living Donor Liver Transplantation
}

\author{
King-Wah Chiu $\mathbb{D}^{1},{ }^{1,2,3}$ Toshiaki Nakano, ${ }^{3,4,5}$ Tsung-Hui Hu, ${ }^{1,2,3}$ \\ Kuang-Den Chen, ${ }^{3,5}$ Li-Wen Hsu, ${ }^{3,5}$ Hock-Liew Eng, ${ }^{3,6}$ Yu-Fan Cheng, ${ }^{3,7}$ \\ Shigeru Goto $\mathbb{D i D}^{3,8,9}$ and Chao-Long Chen ${ }^{3,5}$ \\ ${ }^{1}$ Division of Hepato-Gastroenterology, Department of Internal Medicine, Kaohsiung Chang Gung Memorial Hospital, \\ Kaohsiung, Taiwan \\ ${ }^{2}$ Chang Gung University, College of Medicine, Taoyuan, Taiwan \\ ${ }^{3}$ Liver Transplantation Centre, Kaohsiung Chang Gung Memorial Hospital, Kaohsiung, Taiwan \\ ${ }^{4}$ Graduate Institute of Clinical Medical Sciences, Chang Gung University, Taoyuan, Taiwan \\ ${ }^{5}$ Division of General Surgery, Department of Surgery, Kaohsiung Chang Gung Memorial Hospital and Chang Gung University College \\ of Medicine, Kaohsiung, Taiwan \\ ${ }^{6}$ Department of Pathology, Kaohsiung Chang Gung Memorial Hospital, Kaohsiung, Taiwan \\ ${ }^{7}$ Department of Diagnostic Radiology, Kaohsiung Chang Gung Memorial Hospital, Kaohsiung, Taiwan \\ ${ }^{8}$ Fukuoka Institution of Occupational Health, Nobeoka, Japan \\ ${ }^{9}$ Department of Nursing, Josal International University, Togane, Japan
}

Correspondence should be addressed to King-Wah Chiu; c471026@ms6.hinet.net and Shigeru Goto; etsg0529@gmail.com

Received 19 November 2017; Revised 13 January 2018; Accepted 24 January 2018; Published 19 March 2018

Academic Editor: Dimitrios P. Bogdanos

Copyright (C) 2018 King-Wah Chiu et al. This is an open access article distributed under the Creative Commons Attribution License, which permits unrestricted use, distribution, and reproduction in any medium, provided the original work is properly cited.

\begin{abstract}
To explore subclinical fatty liver disease (FLD) in donors as a possible mechanism leading to FLD in recipients of living donor liver transplantation (LDLT), we extracted thirty donor-recipient pairs' serum DNA and explored the presence of CYP2R1 single nucleotide polymorphism (SNP) rs10741657 and vitamin D receptor (VDR) SNP rs2228530 A/G alleles using real-time polymerase chain reaction. We measured the serum $25(\mathrm{OH}) \mathrm{D}$ concentrations and investigated the CYP2R1 and VDR genotypes of the donors and recipients before and after LDLT for comparison with the histological findings from the donors on wedge biopsy, the recipients' removed native liver, and selective liver biopsy after LDLT. There was a significant difference in low serum $25(\mathrm{OH}) \mathrm{D}$ concentration between the donors and recipients before LDLT and in the recipients before versus after LDLT $(13.90 \pm 8.85$ versus $47.9 \pm 14.88$ versus $11.82 \pm 10.36, P<0.001$ ), and significant difference in FLD was detected on wedge biopsy from the donors and the native liver from the recipients as well as the native liver and follow-up biopsy from the recipients $(P<0.001)$. CYP2R1 and VDR genotype were predominant, both for the AG and for the GG alleles. For the donor VDR SNP rs2228570, low serum 25(OH)D was significantly different between genotypes AA and AG $(P=0.024)$ as well as between genotypes AA and AG plus GG $(P=0.042)$. Our data suggest that donors' VDR rs2228570 AA alleles may play a major role in low serum $25(\mathrm{OH}) \mathrm{D}$ regarding pathological FLD in recipients after LDLT.
\end{abstract}

\section{Introduction}

Nonalcoholic steatohepatitis is strongly associated with low serum 25(OH)D [1-3] and affects patients present with progressive hepatic fibrosis, particularly chronic hepatitis $\mathrm{C}$ infection $[4,5]$. Therefore, hepatocytes appear to be a target that affects serum 25(OH)D levels via the VDR [6]. In the field of the liver transplantation, the new liver from the donor contributes its own characteristics such as CYP2C19 [7], CYP3A4, CYP3A5, MDR-1 [8], and IL28B [9] that can be 
TABLE 1: Clinical profiles of donors and recipients before living donor liver transplantation.

\begin{tabular}{|c|c|c|c|}
\hline Category & Donors $(n=30)$ & Recipients $(n=30)$ & $P$ value \\
\hline Gender (male/female) & $14 / 16$ & $21 / 9$ & $0.115^{*}$ \\
\hline Age (years) & $34.47 \pm 12.73$ & $57.3 \pm 12.81$ & 0.982 \\
\hline Body height (cm) & $165.54 \pm 9.26$ & $164.34 \pm 2.33$ & 0.715 \\
\hline Male & $170.70 \pm 1.56$ & $167.27 \pm 6.35$ & 0.725 \\
\hline Female & $161.03 \pm 5.52$ & $157.50 \pm 6.93$ & 0.173 \\
\hline Body weight (kg) & $62.26 \pm 3.96$ & $63.63 \pm 12.73$ & 0.005 \\
\hline Male & $65.69 \pm 8.06$ & $53.67 \pm 15.88$ & 0.014 \\
\hline Female & $59.26 \pm 5.37$ & $63.63 \pm 12.73$ & 0.243 \\
\hline Body mass index & $22.77 \pm 4.00$ & $23.32 \pm 4.67$ & 0.540 \\
\hline Male & $22.67 \pm 3.14$ & $24.17 \pm 3.07$ & 0.730 \\
\hline Female & $22.85 \pm 3.59$ & $21.32 \pm 4.46$ & 0.691 \\
\hline Idea body weight & $59.67 \pm 9.48$ & $59.67 \pm 3.89$ & 0.632 \\
\hline Male & $65.69 \pm 1.20$ & $63.11 \pm 4.74$ & 0.712 \\
\hline Female & $54.41 \pm 3.68$ & $51.64 \pm 4.59$ & 0.736 \\
\hline Cholesterol, total (mg/dL) & $159.03 \pm 6.36$ & $146.03 \pm 74.95$ & 0.080 \\
\hline Triglycerides (mg/dL) & $95.63 \pm 33.94$ & $117.98 \pm 18.38$ & 0.411 \\
\hline Glucose (FG) (mg/dL) & $91.3 \pm 3.54$ & $105.90 \pm 20.51$ & 0.157 \\
\hline $\operatorname{ALT}(\mathrm{IU} / \mathrm{L})$ & $19.00 \pm 6.36$ & $65.30 \pm 17.68$ & 0.000 \\
\hline GGT (IU/L) & $14.70 \pm 0.71$ & $49.30 \pm 13.44$ & 0.000 \\
\hline Parathyroid hormone level & $38.31 \pm 9.81$ & $40.09 \pm 10.65$ & 0.721 \\
\hline \multicolumn{4}{|l|}{ Liver biopsy } \\
\hline Sample season ${ }^{* *}$ & $7: 8: 8: 7$ & $6: 7: 8: 9$ & \\
\hline Presence of inflammation $(+/-)$ & $1 / 19$ & $4 / 16^{* * *}$ & 0.094 \\
\hline
\end{tabular}

*Fisher's exact test (two-sided). Group statistics by independent samples $t$-test. ALT, alanine aminotransferase; FG, fasting glucose; GGT, gamma-glutamyl transpeptidase. ${ }^{* *}$ Spring : Summer : Autumn : Winter; ${ }^{* * *} 4$ cases presenting with inflammation in liver biopsy were related to the mild degree rejection.

detected in the peripheral blood of the recipients. If the donor presents with characteristics of fatty liver disease (FLD), the recipient will likely demonstrate fatty changes after living donor liver transplantation (LDLT). Because individuals with severe fatty liver or evidence of nonalcoholic steatohepatitis should not be donors for LDLT [10], here we aimed to explore the evidence of subclinical FLD in donors as a possible mechanism leading to recipients developing fatty liver after LDLT.

\section{Materials and Methods}

2.1. Study Population. Thirty adult donor-recipient pairs who underwent LDLT as part of our liver transplantation program were randomly enrolled in the study. Briefly, the mean patient age was 34.5 years (range, 23-59 years) in donors and 57.3 years (range, 35-69 years) in recipients. Subjects included 14 male and sixteen female donors and 21 male and nine female recipients. The causes of liver transplantation were hepatitis $\mathrm{B}$ virus- (HBV-) related liver disease in 25 cases (including four cases of end-stage liver disease [ESLD], 16 of hepatomas, and five of bleeding esophageal varices); primary biliary cirrhosis in three cases; one case of autoimmune hepatitis; and one case of cryptogenic liver cirrhosis.

The inclusion criteria were adult donor-recipient pairs for LDLT of whom the recipients underwent selective liver biopsy after LDLT. All of the donors and recipients provided written informed consent. The exclusion criteria were a history of diabetes mellitus or thyroid disorder; current or past excessive alcohol intake (defined as $>30 \mathrm{~g} /$ day in males and $>20 \mathrm{~g} /$ day in females); treatment with drugs affecting vitamin $\mathrm{D}$; positive serum anti-hepatitis $\mathrm{C}$ virus; pediatric recipients that underwent LDLT; and having undergone deceased donor liver transplantation in either childhood or adulthood.

2.2. Clinical Assessments. Clinical profiles included the following: age, sex, body weight $(\mathrm{kg})$, body height $(\mathrm{cm})$, body mass index (BMI) $\left(\mathrm{kg} / \mathrm{m}^{2}\right)$, ideal body weight $(\mathrm{kg})$, cholesterol $(\mathrm{mg} / \mathrm{dL})$, triglycerides $(\mathrm{mg} / \mathrm{dL})$, fasting glucose $(\mathrm{mg} / \mathrm{dL})$, alanine aminotransferase (ALT) (IU/L), and gamma-glutamyl transpeptidase (IU/L) of the donors and recipients before LDLT (Table 1). Imaging evaluations included ultrasonography (findings of which were defined as negative, mild, moderate, or severe degree of fatty liver) and computed tomography and magnetic resonance imaging (findings of which were defined as negative, $<5 \%, 5-10 \%$, and $>10 \%$ fatty liver) for the potential donors before LDLT and at 1- and 6month follow-up in the recipients after LDLT.

\subsection{Laboratory Assessment}

2.3.1. Serum 25(OH)D. Serum $25(\mathrm{OH}) \mathrm{D}$ levels were investigated in the donors and recipients before LDLT and in 
the recipients 1 and 3 months after. The serum 25(OH)D was measured using a $25(\mathrm{OH})$ vitamin D Enzyme-Linked Immunosorbent Assay kit (ENZO, Enzo Life Sciences Inc., NY, USA). The optical density of each well at $405 \mathrm{~nm}$ was determined within 30 min using a microplate reader. Each sample was assayed in duplicate by a single operator to assess interassay precision. All of the data were processed by an immunoassay software package utilizing a four-parameter logistic curve fitting program. By definition, serum $25(\mathrm{OH}) \mathrm{D}$ levels $\geq 30 \mathrm{ng} / \mathrm{mL}(75 \mathrm{nmol} / \mathrm{L})$ were considered within normal limits in our study.

2.3.2. VDR and CYP2R1 Polymorphisms. Genomic DNA was extracted from the peripheral blood mononuclear cells of the donors and recipients before LDLT and in the recipients 1-3 months after LDLT using a QIAamp DNA Blood Mini Kit (Qiagen, Hilden, Germany). Genotyping was performed to detect the single nucleotide polymorphisms (SNPs) VDR rs2228570 and CYP2R1 rs10741657 using a ready-to-use, manufacturer-validated, predesigned allele discriminating TaqMan SNP assay for polymerase chain reaction (PCR) amplification reactions in clear optical 96-well plates on a 7500 Fast Real-Time PCR system (Applied Biosystems International, Foster City, CA, USA) according to the manufacturer's instructions. The SNPs were selected according to $\mathrm{A} / \mathrm{G}$ allele frequencies and functional clinical implications. All genotypes of the VDR SNP rs2228570 and CYP2R1 SNP rs10741657 were assayed in duplicate to assess interassay precision.

2.4. Ethics. Written informed consent was obtained from each participant. The study protocol conformed to the ethical guidelines of the Declaration of Helsinki and was approved by the ethics review committee of Chang Gung Memorial Hospital (number 201600292B0). None of the transplant donors or recipients was from a vulnerable population.

2.5. Statistics. Data were analyzed using the Statistical Package for the Social Sciences (v. 22.0 for Windows; IBM Corp., Armonk, NY, USA). Student's $t$-test was used to compare the clinical parameters of the donors and recipients before and after the LDLT. Fisher's exact test was used to compare the histological diagnosis between wedge biopsy of the donors and follow-up liver biopsy of the recipients after LDLT. The SNP allele differences in the VDR rs2228570 and CYP2R1 rs10741657 genotypes of the recipients and donors were performed at different time points using the McNemar-Bowker test. Differences were considered statistically significant at values of $P<0.05$.

\section{Results}

3.1. Subclinical Low Serum $25(\mathrm{OH}) D$. There was a significant difference in the low serum $25(\mathrm{OH}) \mathrm{D}$ concentrations between the donors and recipients before LDLT $(13.90 \pm 8.85$ versus $47.9 \pm 14.88 ; P<0.001)$ and in the recipients before versus after LDLT $(47.9 \pm 14.88$ versus $11.82 \pm 10.36 ; P<$ 0.001) (Figure 1). None of the clinical parameters, including
TABLE 2: Fatty liver disease diagnosis made intraoperatively by graft wedge biopsy, imaging on preoperative evaluation of donors, and by follow-up selective liver biopsy and imaging study on the recipients after living donor liver transplantation.

\begin{tabular}{lccccc}
\hline \multirow{2}{*}{$\begin{array}{l}\text { Fatty liver } \\
\text { disease }\end{array}$} & \multicolumn{2}{c}{ Donors, $n=30(\%)$} & \multicolumn{3}{c}{ Recipients, $n=30(\%)$} \\
& Wedge bx & Imaging & Native & F-U bx & Imaging \\
\hline$<5 \%$ & $10(33.3)$ & $8(26.7)$ & $0(0)$ & $8(26.7)$ & $6(20.0)$ \\
$5-10 \%$ & $2(6.7)$ & $3(10)$ & $1(3.3)$ & $3(10)$ & $5(16.7)$ \\
$>10 \%$ & $2(6.7)$ & $1(3.3)$ & $0(0)$ & $1(3.3)$ & $1(3.3)$ \\
Total & $14(46.7)$ & $12(40)$ & $1(3.3)$ & $12(40)$ & $12(40.0)$ \\
\hline Bx + Imaging & \multicolumn{2}{c}{$18(60)^{\mathrm{a}}$} & $1(3.3)^{\mathrm{a}, \mathrm{b}}$ & $19(63.3)^{\mathrm{b}}$ \\
\hline
\end{tabular}

${ }^{\mathrm{a}} P<0.001 ;{ }^{\mathrm{b}} P<0.001$, Fisher's exact test (two-sided); Bx, liver biopsy; F-U, follow-up; image Dx, imaging diagnostic methods including ultrasonography, computed tomography, and magnetic resonance imaging.

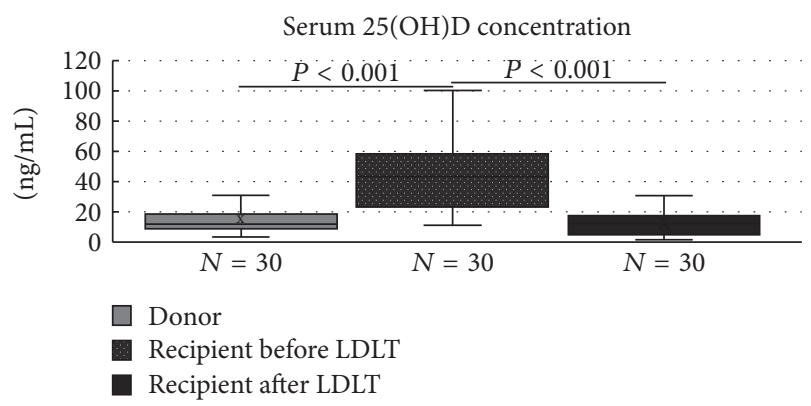

Figure 1: Difference in serum 25(OH)D levels of donor versus recipient before living donation liver transplantation (LDLT) and of recipient before versus after LDLT $(P<0.001)$.

BMI, ideal body weight, and indexes for metabolic disorders (cholesterol, triglyceride, and fasting glucose), differed statistically between the donors and recipients (Table 1).

3.2. Histology Plus Imaging Documented FLD. In the donor group, there was a $60 \%(18 / 30)$ fatty liver disease diagnosis by wedge biopsy $(46.7 \%, 14 / 30)$ and by imaging $(40 \%, 12 / 30)$ with eight cases $(26.7 \%)$ overlapping. The native liver was resected and only 3.3\% (1/30) of cases were associated with $10 \%$ fatty liver in the recipient. In the recipients after LDLT, there was a $63.3 \%(19 / 30)$ rate of fatty liver diagnosis by follow-up selective liver biopsy $(40 \%, 12 / 30)$ and by imaging $(40 \%, 12 / 30)$ with five cases $(16.7 \%)$ overlapping. On the liver tissue histology and imaging studies, FLD differed significantly between the wedge biopsy in the donors and the native liver of the recipients $(P<0.001)$ as well as the native liver and the follow-up selective biopsy of the recipients $(P<0.001)$ (Table 2$)$. By the wedge biopsy proven FLD in liver donors, there was statistical difference in terms of serum 25(OH)D levels between liver donors who have FLD (10.76 $\pm 4.97, n=14)$ and subjects without $(16.64 \pm 7.62$, $n=16)(P=0.0078)$ (Table 3$)$.

3.3. Comparison with CYP2R1 rs10741657/VRD rs2228530 and Serum 25(OH)D. Regarding CYP2R1 SNP rs10741657, the donors and recipients predominantly had AG alleles 


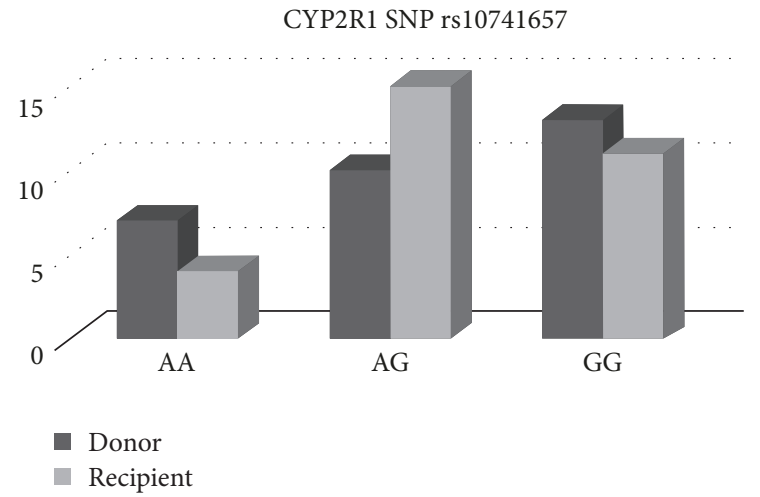

(a) CYP2R1 rs10741657 AA/AG/GG alleles in 30 pairs of donor/ recipient

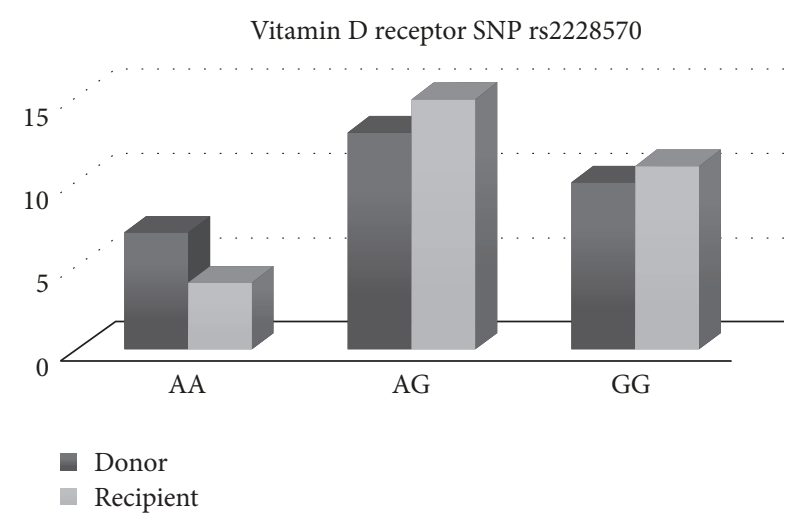

(b) Vitamin D receptor rs2228570 AA/AG/GG alleles in 30 pairs of donor/recipient

Figure 2

TABLE 3: Serum 25(OH)D level between 30 liver donors by wedge biopsy proven with fatty liver disease (FLD) and subjects without.

\begin{tabular}{lccr}
\hline & FLD $(+)$ & FLD $(-)$ & P value \\
$n=14$ & $n=16$ & \\
\hline Serum $25(\mathrm{OH}) \mathrm{D}$ & $10.76 \pm 4.97$ & $16.64 \pm 7.62$ & 0.0078 \\
\hline
\end{tabular}

Student's $t$-test analysis.

$(14 / 13)$ and GG alleles (12/11) but sporadically had AA alleles $(4 / 6)$ (Figure 2(a)). Of the VDR SNP rs2228530 in the donors and recipients, a similar distribution was seen with predominance of AG alleles (12/15) and GG alleles (10/11) but sporadic AA alleles (7/4) (Figure 2(b)). For the donors, the VDR SNP rs2228570 AA genotype was explored with low serum $25(\mathrm{OH}) \mathrm{D}$ concentration compared to those of the AG genotype $(P=0.024)$; and the low serum $25(\mathrm{OH}) \mathrm{D}$ showed also significant difference between the genotype AA and genotype AG plus GG $(P=0.042)$ (Table 4$)$. However, there was no significant distribution by genotype of CYP2R1 rs10741657 in the donors or recipients after LDLT.

\section{Discussion}

By definition, "subclinical" indicates the presence of a disease without the manifestation of symptoms and may be an early stage in the evolution of a disease. The current results suggest that the donors were doing well without evidence of signs of metabolic syndrome such as a high BMI or elevated cholesterol, triglyceride, or fasting glucose levels. In our study, the mean serum $25(\mathrm{OH}) \mathrm{D}$ concentration was $<25 \mathrm{ng} / \mathrm{mL}$ in the healthy donors, representing a subclinical low serum $25(\mathrm{OH}) \mathrm{D}$. A recent report suggested that a low serum $25(\mathrm{OH}) \mathrm{D}$ may be highly associated with nonalcoholic fatty liver disease or metabolic syndrome recognization [2], in which situations he/she should not be a liver donation followed by the donor evaluation in the LDLT setting. Too many studies to explore the nonalcoholic fatty liver disease or nonalcoholic steatohepatitis might be progressed to hepatic fibrosis and liver cirrhosis [11]. The complicating
TABLE 4: Comparison of serum 25(OH)D concentration and single nucleotide polymorphisms (SNP) of vitamin D receptor (VDR) and cytochrome P450 2R1 (CYP2R1) between the donors and recipients before living donor liver transplantation.

\begin{tabular}{lccc}
\hline $\begin{array}{l}\text { Single } \\
\text { nucleotide } \\
\text { polymorphism }\end{array}$ & Allele & $N(\%)$ & $25(\mathrm{OH}) \mathrm{D} \mathrm{ng} / \mathrm{mL}$ \\
\hline Donor & & & \\
& AA & $7(23.3)$ & $10.60 \pm 3.67^{\mathrm{a}, \mathrm{b}}$ \\
VDR rs2228570 & AG & $13(43.3)$ & $16.07 \pm 8.14^{\mathrm{a}, \mathrm{b}}$ \\
& GG & $10(33.3)$ & $13.38 \pm 6.95^{\mathrm{b}}$ \\
CYP2R1 & AA & $4(13.3)$ & $9.23 \pm 6.93$ \\
rs10741657 & AG & $15(50.0)$ & $15.08 \pm 7.79$ \\
& GG & $11(36.7)$ & $13.98 \pm 5.92$ \\
Recipient & & & \\
VDR rs2228570 & AA & $4(13.3)$ & $79.31 \pm 45.41$ \\
& GG & $15(50.0)$ & $39.71 \pm 22.89$ \\
& AA & $7(23.3)$ & $52.25 \pm 16.66$ \\
CYP2R1 & AG & $10(33.3)$ & $43.22 \pm 30.54$ \\
rs10741657 & GG & $13(43.3)$ & $49.15 \pm 37.75$ \\
\hline
\end{tabular}

${ }^{\mathrm{a}}$ AA versus AG, $P=0.024 ;{ }^{\mathrm{b}}$ AA versus AG $+\mathrm{GG}, P=0.042$, Fisher's exact test.

outcomes were more severe and mortality rates were higher in cases of nonalcoholic steatohepatitis particularly in cases of chronic hepatitis $\mathrm{C}$ viral infection [12]. To explore the role of $25(\mathrm{OH}) \mathrm{D}$ in the mechanism of FLD, we excluded the evidence of chronic $\mathrm{C}$ hepatitis relative to end-stage liver disease and alcoholic liver cirrhosis associated with metabolic disorder in our study. A report of the serum $25(\mathrm{OH}) \mathrm{D}$ concentration changing significantly from within the normal limit to a low serum level after LDLT would be the first in the literature. For the FLD investigation of donor livers, imaging studies including computed tomography and magnetic resolution imaging showed that $>15 \%$ fatty liver required a liver biopsy before transplantation and $>20 \%$ fatty 


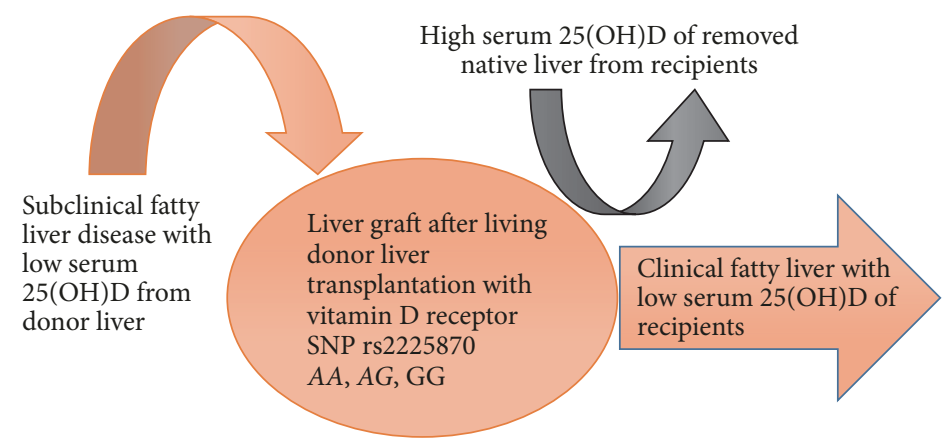

FIGURE 3: Graphic conclusion: a subclinical low serum 25(OH)D level is associated with VDR rs2228570, particularly the AA genotype, of the donors, which may play a major role in FLD in recipients after LDLT.

component to be withdraw for liver donation $[13,14]$. In our study, $60 \%(18 / 30)$ of cases were associated with FLD, and most had a $<5 \%$ to a $5-10 \%$ fatty component. We used the term "subclinical low serum $25(\mathrm{OH}) \mathrm{D}$ with mild degree FLD" to identify such potential donors in this study. According to our previous studies, the characteristic stem cells of liver grafts may carry the specific signal that is transmitted to the recipients $[15,16]$. Barchetta et al. reported that VDR and CYP2R1 may be closely associated with low serum 25(OH)D, particularly in cases of nonalcoholic steatohepatitis [6]. On the outcome of LT patients, 19 (63.3\%) recipients presenting with mild degree abnormality of serum alanine aminotransferase around 48 to 78 IU/L during clinical followed up. Only $4(13.3 \%)$ recipients experience mild rejection controlled by appropriate immunosuppressive agents, and apparently serum $25(\mathrm{OH}) \mathrm{D}$ has no significant effect on organ rejection. In our study, VDR SNP rs2228570 in the donors may carry a signal of FLD present with a low serum $25(\mathrm{OH}) \mathrm{D}$, particularly in cases of AA alleles. This is also a new finding in the current study. On the other hand, CYP2R1 rs10741657 could not have a significant interpretation in our study. Of course, none of our patients met the criteria for nonalcoholic steatohepatitis. Several studies have showed that decreased vitamin D in patients with HBV, primary biliary cholangitis, and autoimmune hepatitis [17-19], but all of the underlying diseases should be corrected after liver transplantation. The current study showed that the evidence of the subclinical FLD from the donor may be one of the major factors to provide the possibility of the FLD to the recipients after LDLT.

Our study has some limitations. The case collection may need to be enhanced over time. The other important factor CYP27A1 SNP is under ongoing study to be present in the future. We try to summarize a graphic conclusion in Figure 3. In conclusion, a subclinical low serum $25(\mathrm{OH}) \mathrm{D}$ level is associated with VDR rs2228570, particularly the AA genotype, of the donors, which may play a major role in FLD in recipients after LDLT.

\section{Abbreviations}

ALT: $\quad$ Alanine aminotransferase

BMI: $\quad$ Body mass index

CYP2R1: Cytochrome P450 subfamily IIR1
ESLD: End-stage liver disease

FG: $\quad$ Fasting glucose

FLD: $\quad$ Fatty liver disease

GGT: Gamma-glutamyl transpeptidase

HBV: Hepatitis B virus

LDLT: Living donor liver transplantation

PCR: $\quad$ Polymerase chain reaction

SNPs: $\quad$ Single nucleotide polymorphisms

25(OH)D: 25-Hydroxyvitamin D

VDR: Vitamin D receptor.

\section{Conflicts of Interest}

The authors declare no conflicts of interest.

\section{Authors' Contributions}

Study concept and design were conducted by King-Wah Chiu and Shigeru Goto; data collection was performed by KingWah Chiu, Toshiaki Nakano, and Shigeru Goto; data analysis and interpretation were performed by King-Wah Chiu, HockLiew Eng, and Yu-Fan Cheng; Toshiaki Nakano, KuangDen Chen, and Li-Wen Hsu performed experiments; and manuscript drafting and critical revision were done by KingWah Chiu, Tsung-Hui Hu, Shigeru Goto, and Chao-Long Chen.

\section{Acknowledgments}

The authors thank Ms. Ching-Yin Huang for her assistance with the data collection. This work was supported by the Chang Gung Memorial Hospital of Taiwan (Grant no. CMRPG8F0621).

\section{References}

[1] M. Manco, P. Ciampalini, and V. Nobili, "Low levels of 25hydroxyvitamin $\mathrm{D}(3)$ in children with biopsy-proven nonalcoholic fatty liver disease.," Hepatology, vol. 51, no. 6, pp. 22292230, 2010.

[2] I. Barchetta, F. Angelico, M. D. Ben et al., "Strong association between non alcoholic fatty liver disease (NAFLD) and low 
$25(\mathrm{OH})$ vitamin $\mathrm{D}$ levels in an adult population with normal serum liver enzymes," BMC Medicine, vol. 9, article 85, 2011.

[3] S. Petta, C. Camma, C. Scazzone et al., "Low vitamin C serum level is related to severe fibrosis and low responsiveness to interferon-based therapy in genotype 1 chronic hepatitis C," Hepatology, vol. 51, no. 4, pp. 1158-1167, 2010.

[4] C. M. Lange, J. Bojunga, E. Ramos-Lopez et al., "Vitamin D deficiency and a CYP27B1-1260 promoter polymorphism are associated with chronic hepatitis $\mathrm{C}$ and poor response to interferon-alfa based therapy," Journal of Hepatology, vol. 54, no. 5, pp. 887-893, 2011.

[5] D. Bitetto, C. Fabris, E. Fornasiere et al., "Vitamin D supplementation improves response to antiviral treatment for recurrent hepatitis C," Transplant International, vol. 24, no. 1, pp. 43-50, 2011.

[6] I. Barchetta, S. Carotti, G. Labbadia et al., "Liver vitamin D receptor, CYP2R1, and CYP27A1 expression: relationship with liver histology and vitamin D3 levels in patients with nonalcoholic steatohepatitis or hepatitis C virus," Hepatology, vol. 56, no. 6, pp. 2180-2187, 2012.

[7] K.-W. Chiu, T. Nakano, T.-H. Hu et al., "Homogenous phenomenon of graft liver CYP2C19 genotypes after living donor liver transplantation," European Journal of Clinical Investigation, vol. 42, no. 4, pp. 352-356, 2012.

[8] K.-W. Chiu, T. Nakano, K.-D. Chen et al., "Pyrosequencing to identify homogeneous phenomenon when using recipients/ donors with different CYP3A $5 * 3$ genotypes in living donor liver transplantation," PLoS ONE, vol. 8, no. 8, Article ID e71314, 2013.

[9] K.-W. Chiu, T. Nakano, K.-D. Chen et al., "Association of IL28B SNPs rs12979860 and rs8099917 on Hepatitis C virus-RNA status in donors/recipients of living donor liver transplantation," PLoS ONE, vol. 11, no. 6, Article ID e0156846, 2016.

[10] K. Yamamoto, Y. Takada, Y. Fujimoto et al., "Nonalcoholic steatohepatitis in donors for living donor liver transplantation," Transplantation, vol. 83, no. 3, pp. 257-262, 2007.

[11] I. Reccia, J. Kumar, C. Akladios et al., "Non-alcoholic fatty liver disease: a sign of systemic disease," Metabolism, vol. 72, pp. 94108, 2017.

[12] C. Boutari, P. Lefkos, V. G. Athyros, A. Karagiannis, and K. Tziomalos, "Nonalcoholic fatty liver disease vs. nonalcoholic steatohepatitis: pathological and clinical implications," Current Vascular Pharmacology, In Press.

[13] Y.-F. Cheng, C.-Y. Yu, H.-Y. Ou et al., "Section 1. Image evaluation of fatty liver in living donor liver transplantation," Transplantation, vol. 97, pp. S3-S6, 2014.

[14] S.-K. Moon, Y.-H. Park, D.-B. Moon et al., "How to perform selective liver biopsy in living liver donors using plain computed tomography," Transplantation, vol. 100, no. 11, pp. 2398-2403, 2016.

[15] K. W. Chiu, T. Nakano, T. H. Hu et al., "CYP2C19 genotypes and graft pathology in recipients after liver transplantation," Annals of Transplantation, vol. 15, pp. 38-43, 2010.

[16] K.-W. Chiu, T. Nakano, K.-D. Chen et al., "Cytochrome P450 in living donor liver transplantation," Journal of Biomedical Science, vol. 22, article 32, 2015.

[17] H. Farnik, J. Bojunga, A. Berger et al., "Low vitamin D serum concentration is associated with high levels of hepatitis $B$ virus replication in chronically infected patients," Hepatology, vol. 58, no. 4, pp. 1270-1276, 2013.

[18] C. Efe, T. Kav, C. Aydin et al., "Low serum vitamin D levels are associated with severe histological features and poor response to therapy in patients with autoimmune hepatitis," Digestive Diseases and Sciences, vol. 59, no. 12, pp. 3035-3042, 2014.

[19] N. Agmon-Levin, R. Kopilov, C. Selmi et al., "Vitamin D in primary biliary cirrhosis, a plausible marker of advanced disease," Immunologic Research, vol. 61, no. 1-2, pp. 141-146, 2014. 


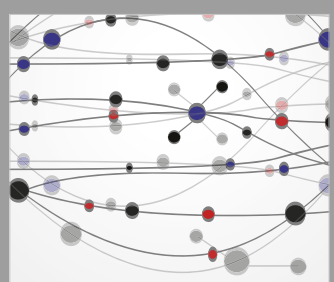

The Scientific World Journal
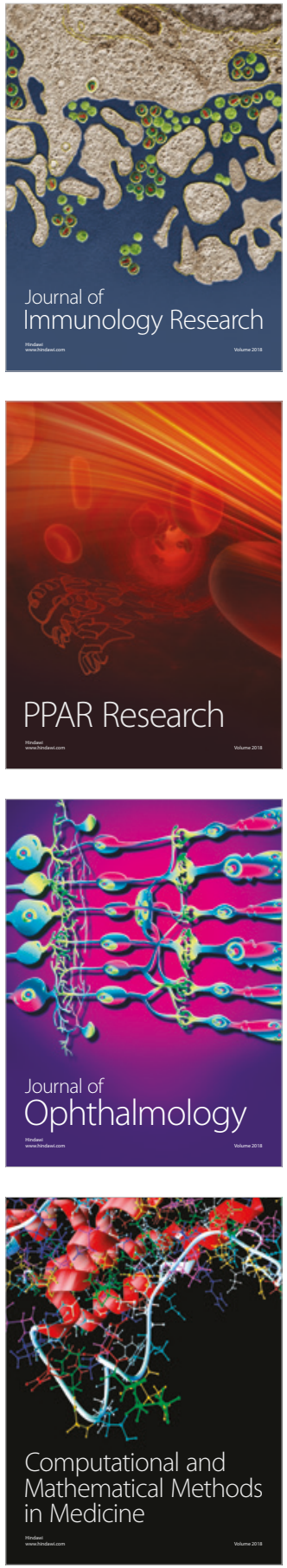

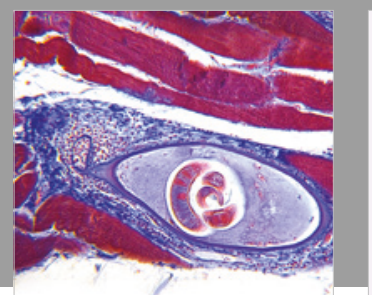

Gastroenterology Research and Practice

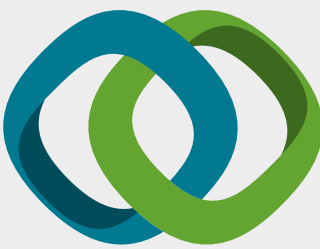

\section{Hindawi}

Submit your manuscripts at

www.hindawi.com
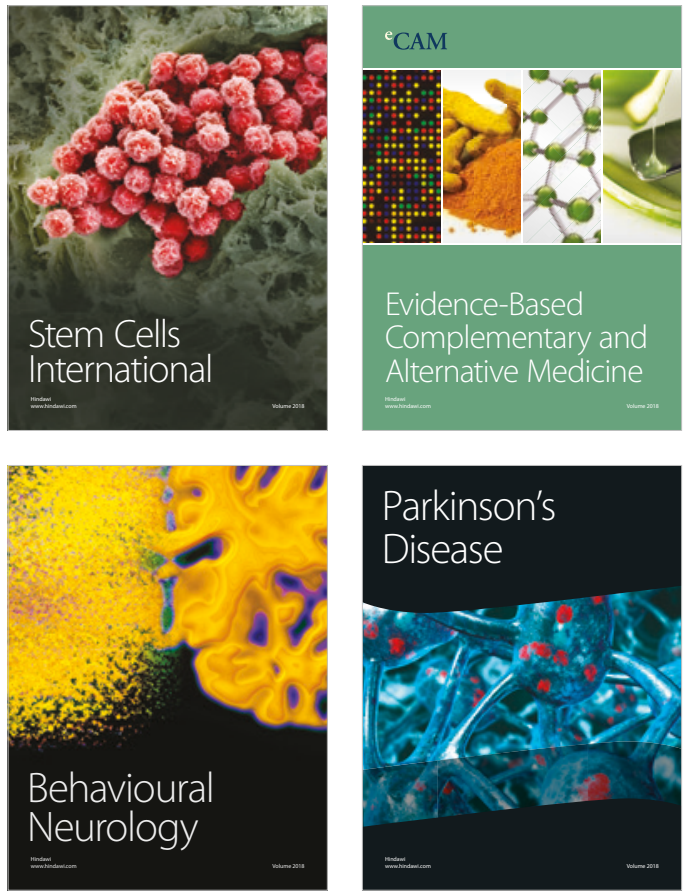

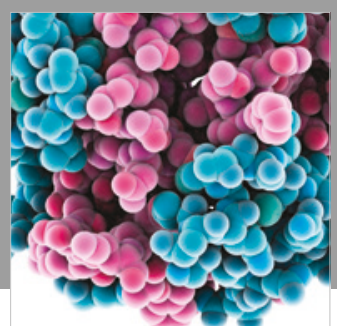

ournal of

Diabetes Research

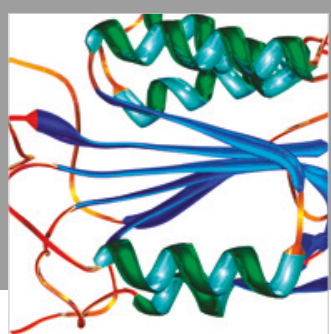

Disease Markers
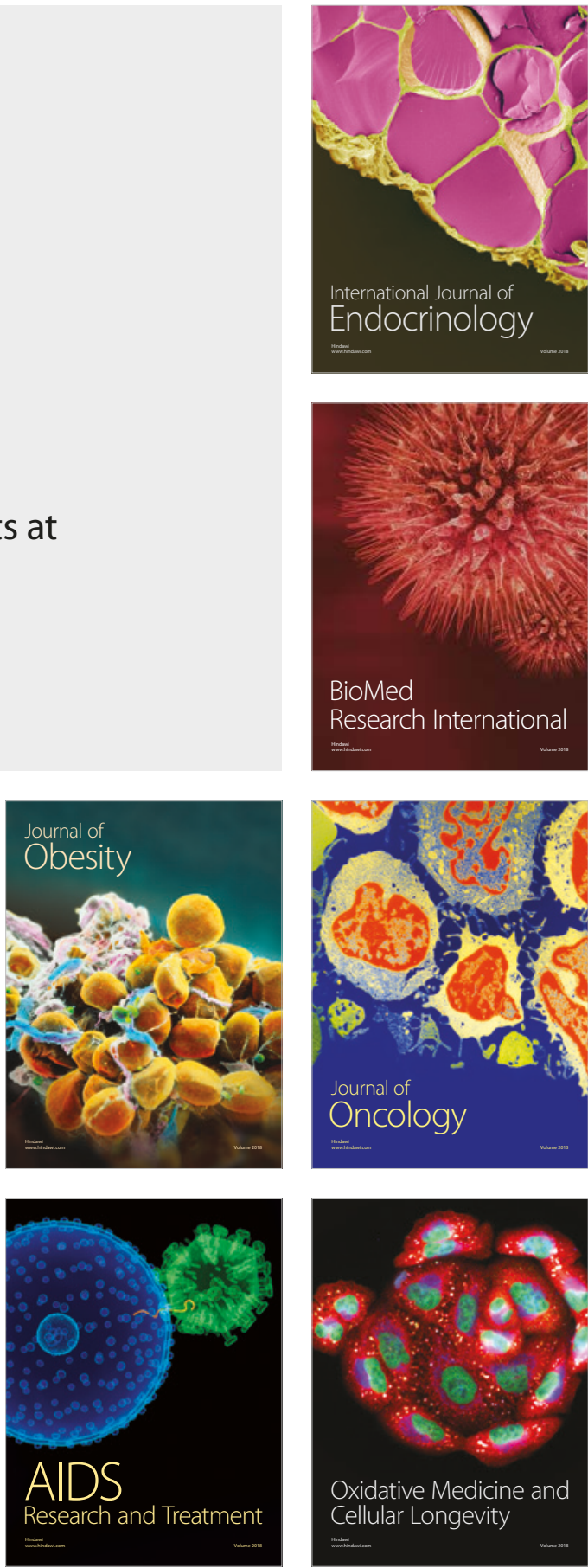